\title{
Increased Predictive Ability of BMI but not Other Risk Factors with Time in Men: 39-Year Follow-Up of Total Mortality in the Oslo Study
}

\author{
Ingar Holme $^{\mathrm{a}}$ Serena Tonstad ${ }^{\mathrm{b}}$ \\ aDepartment of Biostatistics, Epidemiology and Health Economics, Oslo University Hospital \\ Ullevål, Oslo, Norway; ${ }^{b}$ Department of Preventive Cardiology, Oslo University Hospital \\ Ullevål, Oslo, Norway
}

\section{Key Words}

BMI · Blood pressure $\cdot$ Cholesterol · Lipids · Mortality · Oslo Study · Physical activity · Smoking

\begin{abstract}
Objective: Risk factor associations to mortality may change, in part due to removal of highrisk persons. We compared strengths of association and ability of risk factors to predict total mortality across short ( $<15$ years), medium (15-29 years) and long (30-39 years) follow-up. Methods: Cardiovascular risk factors were measured in 1972-1973 in the Oslo Study among 14,846 men born in 1923-1932. Relationships of risk factors to mortality (to 2011) were analyzed using Cox regression models, and receiver operating characteristics (ROC) were estimated. Results: BMI was the only factor that increased strength of association with elapsed time (hazard ratio for $\geq 35 \mathrm{~kg} / \mathrm{m}^{2}$ vs. $22.5-24.9 \mathrm{~kg} / \mathrm{m}^{2}: 1.25$ (95\% CI $0.73-2.17$ ), 1.51 (95\% CI 1.06-2.16) and 3.73 (95\% CI 2.33-5.98) for $<15,15-29$ and 30-39 years, respectively). Other factors lost predictive ability with time. Cigarette smoking was the strongest predictor in all periods. Serum lipids and systolic blood pressure increased risk in most periods, and moderate physical activity was protective to 29 years, but these factors and BMI contributed minimally to ROC. Discussion: Risk factors differed in association strengths and ability to predict mortality over four decades. BMI strengthened its association with time, while cigarette smoking was strongest in all periods.

(C) 2014 S. Karger GmbH, Freiburg
\end{abstract}


Holmea and Tonstadb: Increased Predictive Ability of BMI but not Other Risk Factors with Time in Men: 39-Year Follow-Up of Total Mortality in the Oslo Study

\section{Introduction}

The ability of cardiovascular risk factors to predict cardiovascular and total mortality has been well described. Studies have found that single measurements of blood pressure, cholesterol and other cardiorespiratory risk factors maintain their predictive ability after 3-4 decades [1-5] and demonstrate similar predictive ability across cultures [5]. Not surprisingly though, the predictive ability may change with elapsing time due to changes in risk factors and cohorts [6-13].

During the last decades major changes in risk factor distributions have taken place accompanied by substantial reductions in cardiovascular disease (CVD) mortality [14]. In Norway in 1972-1973 the prevalence of cigarette smoking in the adult male population was above $50 \%$, but is nowadays about $20 \%$. A massive reduction in cigarette smoking is by far the greatest achievement of public health. Furthermore, changes in lifestyle and risk factors appear to explain differences between countries and reflect country mortality trends $[15,16]$. Statins and drugs for blood pressure have likely also contributed to prevention of CVD [14]. The epidemic of obesity has affected practically all subgroups of the population. In this environment, the question arises whether the major CVD risk factors have remained predictive of mortality over decades and whether their relative importance changes with time.

In 1972-1973, 124,846 men born in the years 1923-1932 who were free of CVD and diabetes were screened in the Oslo Study, one of the largest cohorts of CVD risk factors established in the 1970s. We showed previously that single measurements of total cholesterol, blood pressure, and cigarette smoking predicted coronary heart disease mortality after 33 years of follow-up [17]. In the current study we explored the short-, medium- and long-term relationships between CVD risk factors in this population and all-cause mortality during 39 years of follow-up. We aimed to understand whether association strengths and the predictive ability of each factor changed with increasing follow-up periods and compared the factors across time periods.

\section{Material and Methods}

The Oslo Study has been described earlier [18, 19]. Briefly, 25,915 men born in 1923-1932 were invited to a screening examination in 1972-1973. Of the total, 16,203 attended (63\%). Men with a history of CVD, treated hypertension, or diabetes were excluded from analyses as well as men with missing values. This left 14,846 men included in the study. Information about date of death was provided by Statistics Norway up to December 31, 2011 using an 11-digit person number linkage covering the entire Norwegian population. Men who emigrated from Norway were treated as censored observations. This study was approved by the Regional Ethics Committee for scientific research in Norway, the Norwegian Data Inspectorate, and the Ministry of Health. The study complies with the Declaration of Helsinki.

CVD risk factors measured included non-fasting total cholesterol, triglycerides and glucose, systolic and diastolic blood pressure, and number of cigarettes smoked daily. Cholesterol concentration was analyzed using a version of the Lieberman-Burchard method, and triglyceride concentrations were measured with a fluorometric method. Both methods were automated with the Technicon AutoAnalyzer II. The 1972-1973 values were later transformed to modern enzymatic values.

Height and weight were measured and BMI calculated. Responses to the 'Gothenburg' instrument, a previously validated questionnaire regarding physical activity at leisure were elicited [20, 21]. Participants described the extent of movement and exertion in their spare time in an average week during the last year. Activity was categorized as sedentary (read, watch television or other sedentary activities); moderate (walk and cycle including commuting to work and Sunday walks for at least $4 \mathrm{~h} /$ week); intermediate (take part in physical exercise or sport, do heavy gardening work or such for at least $4 \mathrm{~h}$ /week); or high (exercise hard or take part in competitive sport several times a week). 
A subset of the population attended a second screening of CVD risk factors in the year 2000. Of those invited, $37 \%(\mathrm{~N}=6,016)$ attended and had a valid systolic blood pressure taken with mean of $2 \mathrm{nd}$ and $3 \mathrm{rd}$ measurements. We measured tracking of some risk factors over time in this subset as Spearman or Pearson correlation coefficients (r).

\section{Statistical Methods}

Follow-up after the screening examination from May 1, 1972 until December 31, 1973 ended on December 31, 2011 with 9,680 deaths recorded (65\%). Cox regression models were used to estimate mortality hazard ratios of risk factors against reference levels. The risk factors evaluated were number of cigarettes smoked daily (reference, none), category of leisure-time physical activity (reference, sedentary), BMI divided into seven categories (reference, $22.5-24.9 \mathrm{~kg} / \mathrm{m}^{2}$ ), systolic blood pressure, total serum cholesterol and natural log of triglycerides (quintiles and per SD change). In addition age on January 1, 1972 was adjusted for. Non-fasting glucose was not included as multivariate analyses revealed no association with mortality. The proportional hazards assumption of the Cox model was investigated for each risk factor by adding a time $\times$ factor interaction term into a time-dependent Cox regression model, adjusting for the other factors. None of the risk factors showed substantial deviations from proportionality across time. Time of follow-up was partitioned into 3 parts, $<15,15-29$, and 30+ years. Analyses were performed separately for each period and totally. Those alive at entry to each period were used as study population. The length of the last period was chosen to be shorter to boost statistical power in the two first periods.

The predictive value of risk factors to mortality was analyzed by receiver operating characteristics (ROC) statistics. For simplicity we used the prognostic index of the Cox regression model that is the product sum of the estimated regression coefficient and risk factor level across all factors per subject as test variable and death as state variable. This, however, does not take into account the varying prognostic ability across time, but rather represents a crude average for the whole follow-up period. Biases occurring will in all likelihood be small since the purpose of the ROC analyses was to compare ROC areas for different risk factor models, and not ROC levels at various times. This method may be somewhat insensitive when comparing the predictive value of added risk factors since it is based solely on ranks. However, it is much used; so we adopted this method also in our study. We calculated how much each risk factor added to the ROC area over and above the contribution from all the other risk factors. Thus, we first ran a Cox regression model with all factors except the one of interest and noted the ROC. Then we added the factor of interest and reran the model. The added ROC was calculated. As a rule of thumb an added area of 0.02 units is usually required to be of clinical value over and above the other factors.

\section{Results}

Distributions of deaths according to risk factors are given in table 1. Risk factors were more favorable in survivors. Among non-survivors mean levels of systolic blood pressure and triglycerides were lower by increasing time since screening, whereas mean level of total cholesterol increased slightly. Mean level of BMI did not vary by period. Men with BMI between 22.5 and $24.9 \mathrm{~kg} / \mathrm{m}^{2}$ had the lowest proportion of deaths in all periods, with deaths increasing both at lower and higher BMI levels. For cigarette smoking there was a clear doseresponse relationship between proportion of deaths and amount smoked in all periods. Fewer deaths occurred for moderately or highly active men as compared to sedentary men, most markedly during the first 15 years.

In table 2 risks associated with BMI adjusted for the other risk factors are shown. During the first 15 years there was no excess mortality associated with increasing BMI while risk was doubled in the lowest BMI category. A gradual increase in relative risk for higher BMI levels with elapsing time was seen, and the association was strong in the last period. However, BMI had only a marginal impact on the ROC value; so, despite its strong association to mortality late in the follow-up period, its discrimination ability was poor over and above the other factors. 
Holmea and Tonstadb: Increased Predictive Ability of BMI but not Other Risk Factors with Time in Men: 39-Year Follow-Up of Total Mortality in the Oslo Study

Table 1. Baseline variables for men who died in each period versus survivors. $\mathrm{N}(\%)$ is shown for categorical variables and mean (standard deviation) for continuous variables ${ }^{\mathrm{a}}$

\begin{tabular}{|c|c|c|c|c|c|}
\hline Risk factors & Up to 15 years & $15-30$ years & $30-39$ years & Total & Survivors \\
\hline BMI, $\mathrm{kg} / \mathrm{m}^{2}$ & $24.9(3.34)$ & $24.9(3.08)$ & $24.8(2.90)$ & $24.8(3.03)$ & $24.3(2.45)$ \\
\hline $\mathrm{SBP}, \mathrm{mm} \mathrm{Hg}$ & $139.8(18.5)$ & $137.5(17.0)$ & $134.8(15.2)$ & $136.6(16.5)$ & $132.1(13.8)$ \\
\hline $\mathrm{TC}, \mathrm{mmol} / \mathrm{l}$ & $6.37(1.40)$ & $6.52(1.17)$ & $6.42(1.16)$ & $6.50(1.20)$ & $6.20(1.06)$ \\
\hline LnTG, mmol/l & $0.61(0.49)$ & $0.58(0.49)$ & $0.52(0.49)$ & $0.56(0.49)$ & $0.43(0.46)$ \\
\hline \multicolumn{6}{|c|}{ Number of cigarettes/day } \\
\hline 0 & $159(4.5)$ & $722(21.6)$ & $969(36.9)$ & $1,850(52.8)$ & $1,655(47.2)$ \\
\hline $1-4$ & $51(5.9)$ & $210(25.6)$ & $265(43.4)$ & $526(60.4)$ & $345(39.6)$ \\
\hline $5-9$ & $169(7.3)$ & $623(28.9)$ & $673(43.8)$ & $1,465(63.0)$ & $862(37.0)$ \\
\hline $10-14$ & $316(7.7)$ & $1,092(34.4)$ & $1,020(49.1)$ & $2,428(69.6)$ & $1,059(30.4)$ \\
\hline $15-19$ & $227(10.7)$ & $661(34.8)$ & $629(50.7)$ & $1,517(71.3)$ & $611(28.72)$ \\
\hline $20-24$ & $180(10.8)$ & $588(39.6)$ & $470(52.5)$ & $1,238(74.4)$ & $425(25.6)$ \\
\hline$\geq 25$ & $102(11.8)$ & $291(38.1)$ & $263(55.7)$ & $656(75.8)$ & $209(24.2)$ \\
\hline \multicolumn{6}{|c|}{ Physical activity at leisure } \\
\hline Sedentary & $343(11.1)$ & $994(38.0)$ & $862(48.8)$ & $2,199(70.8)$ & 905 (29.2) \\
\hline Light & $675(7.7)$ & $2,493(30.7)$ & $2,543(45.2)$ & $5,711(64.9)$ & $3,087(35.1)$ \\
\hline Moderate & $176(6.5)$ & $650(25.8)$ & $806(43.1)$ & $1,632(60.6)$ & $1,062(39.4)$ \\
\hline High & $10(4.0)$ & $50(20.8)$ & $78(41.1)$ & $138(55.2)$ & $112(48.4)$ \\
\hline
\end{tabular}

SBP = Systolic blood pressure; $\mathrm{TC}=$ total cholesterol $\mathrm{LnTG}=$ natural logarithm of triglycerides.

${ }^{a}$ For variables in years 15-30 deaths in years 0-15 are excluded and for variables in years 30-39 deaths in years $0-30$ are excluded.

Table 2. Relationship between BMI and mortality by length of follow-up, adjusted for other risk factors (age, SBP, TC, LnTG, cigarette smoking, and physical activity at leisure) ${ }^{\mathrm{a}}$

\begin{tabular}{lllll}
\hline BMI, $\mathrm{kg} / \mathrm{m}^{2}$ & $\begin{array}{l}\text { Up to15 years HR } \\
(95 \% \mathrm{CI})\end{array}$ & $\begin{array}{l}15-29 \text { years HR } \\
(95 \% \mathrm{CI})\end{array}$ & $\begin{array}{l}30-39 \text { years HR } \\
(95 \% \mathrm{CI})\end{array}$ & $\begin{array}{l}\text { All years HR } \\
(95 \% \mathrm{CI})\end{array}$ \\
\hline$<18.5$ & $2.49(1.51-4.11)$ & $1.81(1.29-2.55)$ & $2.32(1.57-3.42)$ & $2.09(1.67-2.63)$ \\
$18.5-22.4$ & $1.06(0.90-1.27)$ & $1.07(0.97-1.17)$ & $1.13(1.03-1.23)$ & $1.10(1.03-1.17)$ \\
$22.5-24.9$ & $1(-)$ & $1(-)$ & $1(-)$ & $1(-)$ \\
$25.9-27.4$ & $0.89(0.77-1.03)$ & $1.00(0.92-1.07)$ & $1.14(1.06-1.23)$ & $1.04(0.99-1.10)$ \\
$27.5-29.9$ & $0.92(0.75-1.12)$ & $1.08(0.97-1.20)$ & $1.11(1.00-1.25)$ & $1.07(1.00-1.15)$ \\
$30.0-34.9$ & $0.93(0.70-1.23)$ & $1.16(1.00-1.35)$ & $1.53(1.30-1.80)$ & $1.26(1.13-1.39)$ \\
$\geq 35.0$ & $1.25(0.73-2.17)$ & $1.51(1.06-2.16)$ & $3.73(2.33-5.98)$ & $1.90(1.48-2.45)$ \\
ROC & & & & \\
Total & 0.692 & 0.689 & 0.685 & 0.732 \\
Without BMI & 0.690 & 0.687 & 0.682 & 0.729 \\
Difference & 0.002 & 0.002 & 0.003 & 0.003 \\
\hline
\end{tabular}

$\mathrm{SBP}=$ Systolic blood pressure; $\mathrm{TC}=$ total cholesterol; $\mathrm{LnTG}=$ natural logarithm of triglycerides.

${ }^{a}$ Observation times for deaths in previous periods are excluded. 
Holmea and Tonstadb: Increased Predictive Ability of BMI but not Other Risk Factors with Time in Men: 39-Year Follow-Up of Total Mortality in the Oslo Study

Table 3. Relationship between SBP and mortality by length of follow-up, adjusted for other risk factors (age, BMI, TC, LnTG, cigarette smoking, and physical activity at leisure) ${ }^{\mathrm{a}}$

\begin{tabular}{lllll}
\hline SBP, mm Hg, & $\begin{array}{l}\text { Up to15 years } \\
\text { HR }(95 \% \mathrm{CI})\end{array}$ & $\begin{array}{l}\text { 15-29 years } \\
\text { HR }(95 \% \mathrm{CI})\end{array}$ & $\begin{array}{l}\text { 30-39 years } \\
\text { HR }(95 \% \mathrm{CI})\end{array}$ & $\begin{array}{l}\text { All years } \\
\text { HR }(95 \% \mathrm{CI})\end{array}$ \\
\hline$<122$ & $1(-)$ & $1(-)$ & $1(-)$ & $1(-)$ \\
$122-130$ & $1.23(0.99-1.52)$ & $0.96(0.87-1.07)$ & $1.06(0.96-1.17)$ & $1.04(0.97-1.11)$ \\
$130-136$ & $1.50(1.23-1.84)$ & $1.15(1.04-1.27)$ & $1.06(0.96-1.16)$ & $1.14(1.07-1.221)$ \\
$136-146$ & $1.42(1.15-1.74)$ & $1.28(1.16-1.42)$ & $1.23(1.12-1.35)$ & $1.27(1.19-1.36)$ \\
$\geq 146$ & $2.11(1.73-2.58)$ & $1.61(1.45-1.78)$ & $1.34(1.21-1.49)$ & $1.54(1.44-1.65)$ \\
Per SD (15.8) & $1.25(1.18-1.32)$ & $1.19(1.15-1.23)$ & $1.12(1.08-1.15)$ & $1.17(1.15-1.20)$ \\
ROC, linear model & & & & \\
Total & 0.692 & 0.689 & 0.685 & 0.732 \\
Without SBP & 0.679 & 0.682 & 0.681 & 0.725 \\
Difference & 0.013 & 0.007 & 0.004 & 0.007 \\
\end{tabular}

SBP = Systolic blood pressure; TC = total cholesterol; LnTG = natural logarithm of triglycerides.

abservation times for deaths in previous periods are excluded.

Table 4. Relationship between TC and mortality by length of follow-up, adjusted for other risk factors (age, BMI, SBP, LnTG, cigarette smoking, and physical activity at leisure) ${ }^{\mathrm{a}}$

\begin{tabular}{lllll}
\hline TC, mmol $/ \mathrm{l}$ & $\begin{array}{l}\text { Up to15 years } \\
\text { HR }(95 \% \mathrm{CI})\end{array}$ & $\begin{array}{l}\text { 15-29 years } \\
\text { HR }(95 \% \mathrm{CI})\end{array}$ & $\begin{array}{l}30-39 \text { years } \\
\text { HR }(95 \% \mathrm{CI})\end{array}$ & $\begin{array}{l}\text { All years HR } \\
(95 \% \mathrm{CI})\end{array}$ \\
\hline$<5.45$ & $1(-)$ & $1(-)$ & $1(-)$ & $1(-)$ \\
$5.45-6.03$ & $0.98(0.80-1.20)$ & $0.98(0.89-1.09)$ & $1.07(0.97-1.19)$ & $1.02(0.95-1.09)$ \\
$6.03-6.57$ & $1.02(0.84-1.24)$ & $1.01(0.91-1.12)$ & $1.05(0.95-1.17)$ & $1.03(0.96-1.10)$ \\
$6.57-7.26$ & $1.13(0.93-1.38)$ & $0.99(0.90-1.10)$ & $1.08(0.97-1.20)$ & $1.04(0.97-1.12)$ \\
$\geq 7.26$ & $1.38(1.14-1.67)$ & $1.09(0.99-1.21)$ & $1.18(1.06-1.32)$ & $1.16(1.08-1.25)$ \\
Per SD (1.16) & $1.15(1.09-1.21)$ & $1.04(1.00-1.07)$ & $1.05(1.02-1.09)$ & $1.06(1.04-1.09)$ \\
\hline ROC, linear model & & & & \\
Total & 0.692 & 0.689 & 0.685 & 0.732 \\
Without TC & 0.687 & 0.689 & 0.684 & 0.731 \\
Difference & 0.005 & 0.000 & 0.001 & 0.001 \\
\hline
\end{tabular}

SBP = Systolic blood pressure TC = total cholesterol LnTG = natural logarithm of triglycerides.

a Observation times for deaths in previous periods are excluded.

Systolic blood pressure associated strongly to mortality during the early part of the period (adjusted for the other risk factors), but the mortality risk gradient declined in the later periods (table 3). When assessed according to discrimination ability, it followed cigarette smoking (see below). However, its contribution to ROC was less than 0.02, even in the first period.

Total serum cholesterol showed a somewhat stronger relationship to mortality as compared to (log) triglycerides in the first period (after adjustment for other risk factors), while the latter was somewhat stronger in the second period (tables 4 and 5). None of the lipid factors added notable discrimination value to the other risk factors in any period.

Table 6 shows relative risks according to cigarette smoking, adjusted for the other risk factors. In all periods the dose-response relationship was strong though it weakened with time, and flattened off at the higher consumption levels, especially in the last two periods. 
Holmea and Tonstadb: Increased Predictive Ability of BMI but not Other Risk Factors with Time in Men: 39-Year Follow-Up of Total Mortality in the Oslo Study

Table 5. Relationship between LnTG and mortality by length of follow-up, adjusted for other risk factors (age, BMI, SBP, TC, cigarette smoking, and physical activity at leisure) ${ }^{\mathrm{a}}$

\begin{tabular}{lllll}
\hline LnTG, mmol/l & $\begin{array}{l}\text { Up to15 years } \\
\text { HR }(95 \% \mathrm{CI})\end{array}$ & $\begin{array}{l}\text { 15-29 years } \\
\text { HR }(95 \% \mathrm{CI})\end{array}$ & $\begin{array}{l}\text { 30-39 years } \\
\text { HR }(95 \% \mathrm{CI})\end{array}$ & $\begin{array}{l}\text { All years } \\
\text { HR }(95 \% \mathrm{CI})\end{array}$ \\
\hline$<1.11$ & $1(-)$ & $1(-)$ & $1(-)$ & $1(-)$ \\
$1.11-1.45$ & $0.98(0.80-1.20)$ & $1.05(0.95-1.17)$ & $1.07(0.96-1.18)$ & $1.05(0.98-1.12)$ \\
$1.45-1.84$ & $1.11(0.92-1.36)$ & $1.13(1.02-1.26)$ & $0.98(0.88-1.09)$ & $1.06(0.99-1.14)$ \\
$1.84-2.46$ & $1.16(0.95-1.41)$ & $1.26(1.14-1.40)$ & $1.05(0.95-1.18)$ & $1.16(1.08-1.24)$ \\
$\geq 2.46$ & $1.05(0.99-1.12)$ & $1.30(1.17-1.45)$ & $1.17(1.05-1.31)$ & $1.22(1.13-1.31)$ \\
Per SD LnTG (0.47) & $1.05(0.99-1.12)$ & $1.10(1.06-1.14)$ & $1.06(1.02-1.10)$ & $1.07(1.03-1.10)$ \\
ROC, linear model & & & & \\
Total & 0.692 & 0.689 & 0.685 & 0.732 \\
Without LnTG & 0.691 & 0.688 & 0.684 & 0.731 \\
Difference & 0.001 & 0.001 & 0.001 & 0.001 \\
\hline
\end{tabular}

$\mathrm{SBP}=$ Systolic blood pressure; $\mathrm{TC}$ = total cholesterol; $\mathrm{LnTG}=$ natural logarithm of triglycerides.

${ }^{a}$ Observation times for deaths in previous periods are excluded.

Table 6. Relationship between amount of cigarette smoking (no/day) and mortality by length of follow-up, adjusted for other risk factors (age, BMI, SBP, TC, LnTG, and physical activity at leisure) ${ }^{\mathrm{a}}$

\begin{tabular}{|c|c|c|c|c|}
\hline Number of cigarettes per da & $\begin{array}{l}\text { yUp to } 15 \text { years } \\
\text { HR }(95 \% \mathrm{CI})\end{array}$ & $\begin{array}{l}15-29 \text { years } \\
\text { HR }(95 \% \mathrm{CI})\end{array}$ & $\begin{array}{l}30-39 \text { years } \\
\text { HR }(95 \% \mathrm{CI})\end{array}$ & $\begin{array}{l}\text { All years HR } \\
(95 \% \mathrm{CI})\end{array}$ \\
\hline 0 & $1(-)$ & $1(-)$ & $1(-)$ & $1(-)$ \\
\hline $1-4$ & $1.43(1.02-2.01)$ & $1.31(1.10-1.56)$ & $1.24(1.05-1.46)$ & $1.29(1.15-1.44)$ \\
\hline $5-9$ & $1.77(1.44-2.17)$ & $1.59(1.42-1.77)$ & $1.53(1.37-1.70)$ & $1.57(1.46-1.69)$ \\
\hline $10-14$ & $1.94(1.65-2.29)$ & $2.09(1.92-2.28)$ & $1.78(1.63-1.95)$ & $1.92(1.82-2.04)$ \\
\hline $15-19$ & $2.50(2.10-2.98)$ & $2.06(1.86-2.28)$ & $1.88(1.70-2.09)$ & $2.03(1.90-2.17)$ \\
\hline $20-24$ & $2.70(2.23-3.26)$ & $2.68(2.41-2.98)$ & $2.14(1.90-2.43)$ & $2.46(2.29-2.65)$ \\
\hline$\geq 25$ & $2.81(2.17-3.64)$ & $2.46(2.10-2.86)$ & $2.00(1.66-2.40)$ & $2.31(2.07-2.57)$ \\
\hline \multicolumn{5}{|l|}{ ROC } \\
\hline Total & 0.692 & 0.689 & 0.685 & 0.732 \\
\hline Without cigarette smoking & 0.654 & 0.646 & 0.656 & 0.690 \\
\hline Difference & 0.038 & 0.043 & 0.029 & 0.042 \\
\hline
\end{tabular}

$\mathrm{SBP}=$ Systolic blood pressure; $\mathrm{TC}=$ total cholesterol; $\mathrm{LnTG}=$ natural logarithm of triglycerides.

${ }^{a}$ Observation times for deaths in previous periods are excluded.

Excluding cigarette smoking from the full prognostic model had a substantial reduction effect on the discrimination ability of the risk factors with somewhat less ROC reduction in the last period.

For physical activity (table 7), a protective effect of moderate activity was seen up to 29 years. Physical activity at leisure did not improve discrimination ability when added to the other factors.

The correlation coefficients for risk factors that were tracked in the second screening were Spearman's $r=0.69$ for BMI (which increased by $1.92 \mathrm{~kg} / \mathrm{m}^{2}(\mathrm{SD}=2.38$ )) between screenings, Spearman's $r=0.26$ for physical activity, and Pearson's $r=0.34$ for systolic blood pressure. Thus, tracking was much stronger for BMI than for the other factors, contributing to less within-person variability across time and hence greater predictive ability of BMI. 
Holmea and Tonstadb: Increased Predictive Ability of BMI but not Other Risk Factors with Time in Men: 39 -Year Follow-Up of Total Mortality in the Oslo Study

Table 7. Relationship between category of physical activity at leisure and mortality by length of follow-up, adjusted for other risk factors (age, BMI, SBP, TC, LnTG, and cigarette smoking) ${ }^{\mathrm{a}}$

\begin{tabular}{lllll}
\hline Physical activity at leisure & $\begin{array}{l}\text { Up to15 years HR } \\
(95 \% \mathrm{CI})\end{array}$ & $\begin{array}{l}15-29 \text { years } \\
\text { HR }(95 \% \mathrm{CI})\end{array}$ & $\begin{array}{l}30-39 \text { years } \\
\text { HR }(95 \% \mathrm{CI})\end{array}$ & $\begin{array}{l}\text { All years HR } \\
(95 \% \mathrm{CI})\end{array}$ \\
\hline None & $1(-)$ & $1(-)$ & $1(-)$ & $1(-)$ \\
Light & $0.77(0.68-0.88)$ & $0.93(0.86-1.01)$ & $0.96(0.89-1.05)$ & $0.92(0.87-0.97)$ \\
Moderate & $0.76(0.63-0.91)$ & $0.85(0.77-0.94)$ & $1.02(0.92-1.14)$ & $0.90(0.84-0.97)$ \\
High & $0.57(0.30-1.08)$ & $0.83(0.62-1.11)$ & $1.15(0.89-1.48)$ & $0.93(0.77-1.11)$ \\
ROC & & & & \\
Total & 0.692 & 0.689 & 0.685 & 0.732 \\
Without physical activity & 0.689 & 0.689 & 0.685 & 0.732 \\
Difference & 0.003 & 0.000 & 0.000 & 0.000 \\
\hline
\end{tabular}

SBP = Systolic blood pressure; $\mathrm{TC}=$ total cholesterol; $\mathrm{LnTG}=$ natural logarithm of triglycerides.

${ }^{a}$ Observation times for deaths in previous periods are excluded.

\section{Discussion}

Our findings suggest that classical CVD risk factors predicted mortality but predictive ability weakened over nearly four decades, with the exception of BMI, which strengthened its association over time. Across factors, cigarette smoking showed the strongest association to mortality, followed by systolic blood pressure. BMI, lipids, and physical activity did not add predictive value over and above the other factors in any period. The main emphasis of the Oslo Study was to study CVD risk factors and prevention of cardiovascular risk. Thus, the factors studied here were selected on that basis. The strengths of the study include the large number of participants, long follow-up and subsequent large numbers of death.

Several CVD risk factor follow-up cohorts were established in the 1970s - the Oslo cohort is one of the largest but included only men unfortunately. The contemporary Renfrew and Paisley survey of residents aged 45-64 years found similar relative risks in women as men but lower absolute and attributable risks than in men [22]. The Multifactor Primary Prevention study from Gothenburg, Sweden, enrolled men aged 45-55 years in 1970 [11]. Conventional risk factors were associated with increased risk of coronary events for most of 28 years, with the exception of BMI and physical activity. In the British Regional Heart Study of 7,735 men aged 40-59 years established in the late 1970s, most major risk factors predicted coronary heart disease (CHD) events occurring in up to 15 years of follow-up, with some attenuation over time [8]. The Seven Countries Study which enrolled men in the late 1950s found generally monotonic associations of serum cholesterol with CHD [10], persisting up to 30-35 years in some cohorts $[9,10]$ though a strong relation during the first 10 -year period weakened in the remaining 25 years in the European cohorts [13]. Varying results in studies may reflect varying endpoints and other methodological differences, but generally our findings agree with previous ones in regard to conventional risk factors $[9,10,11,13]$.

A natural selection of survivors will inevitably take place in such analyses, and the men most sensitive to high exposure levels of a risk factor will die first. A dilution of the associations is therefore expected when follow-up is as long as two decades or more after screening. Another source of dilution is the potential for progressively larger changes in risk factor levels to take place with longer follow-up, usually making associations weaker. In our study the exception was seen with BMI, as BMI increased its strength of association with mortality especially in the final period of 30-39 years (though remaining a much weaker predictor than smoking). 
Holmea and Tonstadb: Increased Predictive Ability of BMI but not Other Risk Factors with Time in Men: 39 -Year Follow-Up of Total Mortality in the Oslo Study

Our findings agree with the Finnish study of 1,619 men which found that serum cholesterol and smoking predicted CHD death early and late during 30 years of follow-up, while BMI was only associated with CHD death after 20 years [7]. Likewise the Chicago Heart Association study that enrolled over 9,000 men (and over 7,000 women) found that in men (though not in women), the influence of BMI on cardiovascular death was strengthened with time [12]. We showed previously that BMI predicted fatal CHD 16-21 years after baseline in this same population, but not during the initial decade and a half of follow-up [23]. We now extend these observations to total mortality. While it has been argued that the association between obesity and disease may change over time, for example due to improved treatment of risk factors, consistent evidence for this notion has not been found [24]. In agreement, we rather found increasing effect of BMI with time.

BMI is a generalized type of risk factor marking a number of metabolic changes, leading not just to CVD and diabetes but also to cancer and renal failure among other major causes. Among conventional risk factors, BMI is the one that has increased markedly during the decades of the study, and tracking of BMI is rather strong (correlation for two measurements taken 28 years apart $=0.69$ ). These observations suggest that those with high BMI at screening probably attained even higher levels during follow-up. In the 30- to 39-year follow-up period men whose baseline BMI was above $35 \mathrm{~kg} / \mathrm{m}^{2}$ experienced a substantial excess mortality (hazard ratio 3.7). It seems that middle aged men with extreme obesity may tolerate this for decades with no major excess mortality risk, but entering older age with this long lasting burden cumulated in excess mortality compared to their less heavy contemporaries. Clinically, this delay may provide an opportunity for a gradual rather than a rapid weight loss in order to reduce risk.

Almost all studies show a U-shaped relation between BMI and total mortality $[25,26]$, with the exception of subgroups of very healthy men [27]. The U-shape has been explained in part by antecedent illness, and the first few years of follow-up are often excluded from analyses to remove this effect. However, 15 years or more of follow-up may be needed before the U-shape disappears [28]. In the current study, this U-shape was evident even after 30-39 years of follow-up with excess mortality in the two lowest BMI categories. Not all studies looking at divided periods of follow-up have found an effect of BMI on mortality with time; however, this may be due to differences in methodology, cohorts, and insufficient power, or other explanations. Recent analyses have shown that when disparate cohort mortality and age-related survey selection bias are accounted for in Cox survival models, the obesitymortality relationship grows stronger with age [29].

In regard to the current findings, we do not know whether BMI per se changed or the predictive value of BMI at a given time point (baseline) changed. Probably both are involved in the observed gradients, but since BMI has increased in contrast to the other factors [23], it seems more likely that the influence of increased BMI is the dominant component. Results from a separate analysis in those who attended the year 2000 screening and their 12-year follow-up showed a weaker relationship between the upper part of the BMI distribution and total mortality than the relationship found in the last period of this study. Whereas risk ratios were 1.53 (1.30$1.80)$ and $3.73(2.33-5.98)$ in the two upper categories of BMI as compared to reference group (table 2), these were only $1.15(0.99-1-33)$ and $1.26(0.86-1.83)$ in the 12-year follow-up of the rescreened population. However, such a comparison is difficult to make since there was a marked selection of healthy men who participated in the second screening.

Smoking was the strongest and most consistent predictor of mortality. Our findings are in line with other studies showing smoking to be one of the strongest determinants of mortality among risk factors $[4,7-9,16]$, a result which was already published when we discussed 33-year follow-up of total mortality [30]. This was no surprise given the detrimental effects of cigarette smoking on CVD, cancer, diabetes, accidents, and other causes. Nearly one half of 
the men in this cohort reported smoking cigarettes at baseline. Smoking rates in Norway in general declined in the course of follow-up, but the decline was slow during the first 20 years and accelerated in the latter 20 years, explaining in part the flattening of risk and even risk reduction seen at high consumption levels in the last period.

The protective effect of moderate physical activity at leisure was present in up to three decades of follow-up, independent of other risk factors. Due to the small number of men in the high category of activity, precise estimates of effects in this group could not be made. Less dramatic changes in the Norwegian population levels of activity have been noted during these decades than those seen with smoking, though some polarization has occurred. Larger proportions of the population report moderate to very high and very low activity [31]. Tracking was relatively low with Spearman's correlation for measurements taken between the two screenings of 0.27 , suggesting an explanation for a dilution effect on the predictive ability of physical activity in the long term. In comparison, cardiorespiratory fitness, not measured in the current study, has been associated with total mortality across three decades of follow-up in men, with some attenuation with time [32].

Systolic blood pressure was strongly associated to mortality, but its strength tapered off with time. Tracking was relatively low (correlation $=0.35$ ) which indicates large changes in systolic blood pressure. One main reason may be the change from no use of antihypertensive drugs at screening to one-third of attending men treated in the year 2000, along with other factors reducing the strengths of association between systolic blood pressure and mortality. On the other hand, the mean level of systolic blood pressure increased by $10 \mathrm{~mm} \mathrm{Hg}$ during the 28 years for those who attended both screenings, leading to increased risk.

The two lipid factors total serum cholesterol and (non-fasting) triglycerides showed the strongest associations in the first period, with weak associations thereafter. Their risk gradients across quintiles were clearly weaker than for systolic blood pressure. A dilution effect on risk by use of cholesterol-lowering medications may also have influenced results, especially in the last period, since $20 \%$ of those who participated at the screening in year 2000 used such drugs versus none at baseline. Total serum cholesterol fell by $0.47 \mathrm{mmol} / \mathrm{l}$ between screenings in 1972-1973 and 2000, while non-fasting triglycerides were unchanged between screenings.

\section{Study Limitations}

Risk factors addressed in this study were limited by what was known in 1972-1973. Thus, lipid subfractions, markers of inflammation, waist circumference, and other measures were not available. Though the response rate was high, responders constituted most likely the healthiest part of the population and the exclusion of non-responders may bias estimates of risk factors in the population.

The availability of only a single measure of risk factors at baseline results in regression dilution bias, which means that associations between risk factors and mortality are likely to be underestimated [33]. We did not have carboxyhemoglobin measurements that may capture more of the risk associated with cigarette smoking than self-reported smoking alone [34].

\section{Conclusions}

Cigarette smoking was the strongest risk factor for mortality in all periods of follow-up. BMI became progressively more important with time, unlike all other risk factors, that tended to lose association strength with time. Systolic blood pressure was the second strongest risk factor but lost its predictive ability with time. Total serum cholesterol was associated with mortality in all periods. While cholesterol was strongest in the first period, triglycerides as a predictor was strongest in the second period. Moderate physical activity was protective through the first two periods of follow-up. Only cigarette smoking contributed substantially to ROC. 
Holmea and Tonstadb: Increased Predictive Ability of BMI but not Other Risk Factors with Time in Men: $39-$ Year Follow-Up of Total Mortality in the Oslo Study

\section{Disclosure Statement}

The authors have no conflicts of interest to declare.

\section{References}

$\checkmark 1$ Anderson KM, Castelli WP, Levy D: Cholesterol and mortality. 30 years of follow-up from the Framingham Study. JAMA 1987;257:2176-2180.

2 Whiteley L, Padmanabhan S, Hole D, Isles C: Should diabetes be considered a coronary heart disease risk equivalent? Results from 25 years of follow-up in the Renfrew and Paisley survey. Diabetes Care 2005;28: 1588-1593.

-3 Menotti A, Puddu PE, Lanti M, Maiani G, Fidanza F: Cardiovascular risk factors predict survival in middle-aged men during 50 years. Eur J Intern Med 2013;24:67-74.

-4 Ferrie JE, Singh-Manoux A, Kvimäki M, Mindell J, Breeze E, Davey Smith G, Shipley MJ: Cardiorespiratory risk factors as predictors of 40-year mortality in women and men. Heart 2009;95:1250-1257.

5 Puddu PE, Menotii A, Tolonen H, Nedeljkovic S, Kafatos AG: Determinants of 40-year all-cause mortality in the European cohorts of the Seven Countries Study. Eur J Epidemiol 2011;26:595-608.

-6 Benfante RJ, Reed DM, MacLean CJ, Yano K: Risk factors in middle age that predict early and late onset of coronary heart disease. J Clin Epidemiol 1989;42:95-104.

7 Pekkanen J, Tervahauta M, Nissinen A, Karvonen MJ: Does the predictive value of baseline coronary risk factors change over a 30-year follow-up? Cardiology 1993;82:181-190.

-8 Wannamethee SG, Shaper AG, Whincup PH, Walker M: Role of risk factors for major coronary heart disease events with increasing length of follow up. Heart 1999;91:374-379.

-9 Menotti A, Kromhout D, Blackburn H, Jacobs D, Lanti M: Early and late coronary deaths in the US Railroad study predicted by major coronary risk factors. Eur J Cardiovasc Prevention Rehab 2004;11:382-388.

10 Menotti A, Lanti M: Coronary risk factors predicting early and late coronary deaths. Heart 2003;89:19-24.

11 Wilhelmsen L, Lappas G, Rosengren A: Risk of coronary events by baseline factors during 28 years follow-up and three periods in a random population sample of men. J Intern Med 2004;256:298-307.

12 Berry JD, Dyer A, Carnethon M, Tian L, Greenland P, Lloyd-Jones DM: Association of traditional risk factors with cardiovascular death across 0 to 10,10 to 20, and >20 years follow-up in men and women. Am J Cardiol 2008;191:89-94.

13 Menotti A, Lanti M, Kromhout D, Kafatos A, Nedeljkovic S, Nissinen A: Short and long term association of a single serum cholesterol measurement in middle-aged men in prediction of fatal coronary and other cardiovascular events: a cross-cultural comparison through Europe. Eur J Epidemiol 2005;20:597-604.

14 Ford ES, Capewell S: Proportion of the decline in cardiovascular mortality disease due to prevention versus treatment: public health versus clinical care. Annu Rev Public Health 2011;32:5-22.

15 Menotti A, Puddu PE: Coronary heart disease differences across Europe: a contribution from the Seven Countries Study. J Cardiovasc Med 2013;14:767-772.

16 Menotti A, Lanti M, Kromhout D, Blackburn H, Nissinen A, Dontas A, Kafatos A, Nedeljkovic S, Adachi H: Fortyyear coronary mortality trends and changes in major risk factors in the first 10 years of follow-up in the seven countries study. Eur J Epidemiol 2007;22:747-754.

17 Holme I, Tonstad S: Association of coronary heart disease mortality with risk factors according to length of follow-up and serum cholesterol level in men; the Oslo Study cohort. Eur J Prev Cardiol 2011;20:168-175.

18 Leren P, Askevold EM, Foss OP, Froili A, Grymyr D, Helgeland S, Hjermann I, Holme I, Lund-Larsen PG, Norum KR: The Oslo Study. Cardiovascular disease in middle-aged and young Oslo men. Acta Med Scand Suppl 1975; 588:1-38.

19 Holme I, Helgeland A, Hjermann I, Leren P, Lund-Larsen PG: Four and two-thirds years incidence of coronary heart disease in middle-aged men. The Oslo Study. Am J Epidemiol 1980;112:149-160.

20 Saltin B, Grimby G: Physiological analysis of middle-aged and old former athletes. Circulation 1968;38:11041115.

21 Wilhelmsen L, Tibblin G, Aurell M, Bjure J, Ekström-Jodal B, Grimby G: Physical activity, physical fitness and risk of myocardial infarction. Adv Cardiol 1976;18:17-30.

22 Isles CG, Hole DJ, Hawthorne VM, Lever AF: Relation between coronary risk and coronary mortality in women of the Renfrew and Paisley survey: comparison with men. Lancet 1992;339:702-706.

-23 Håheim LL, Tonstad S, Hjermann I, Leren P, Holme I: Predictiveness of body mass index for fatal coronary heart disease in men according to length of follow-up: a 21-year prospective cohort study. Scand J Public Health 2007;35:4-10.

24 de Hollander EL, Bogers RP, Boshuizen HC, Rosengren A, Shipley MJ, Knekt P, Ducimetrière P, Menotti A, de Groot LC, Bemelmans WJ; BMI-CHD collaboration investigators: Influence of calendar period on the association between BMI and coronary heart disease: a meta-analysis of 31 cohorts. Obesity (Silver Spring) 2013; 21:865-880. 
Holmea and Tonstadb: Increased Predictive Ability of BMI but not Other Risk Factors with Time in Men: 39-Year Follow-Up of Total Mortality in the Oslo Study

25 Prospective Studies Collaboration, Whitlock G, Lewington S, Sherliker P, Clarke R, Emberson J, Halsey J, Qizilbash N, Collins R, Peto R: Body-mass index and cause-specific mortality in 900000 adults: collaborative analyses of 57 prospective studies. Lancet 2009;373:1083-1096.

26 Song Z, Pitkäniemi J, Gao W, Heine RJ, Pyörälä K, Söderberg S, Stehouwer CD, Zethelius B, Tuomilehto J, Laatikainen T, Tabák AG, Qiao Q; DECODE Study Group: Relationship between body mass index and mortality among Europeans. Eur J Clin Nutr 2012;66:156-165.

27 Singh PN, Lindsted KD, Fraser GE: Body weight and mortality among adults who never smoked. Am J Epidemiol 1999;150:1152-1164.

28 Lindsted KD, Singh PN: Body mass and 26 y risk of mortality among men who never smoked: a re-analysis among men from the Adventist Mortality Study. Int J Obes Relat Metab Disord 1998;22:544-548.

29 Masters RK, Powers DA, Link BG: Obesity and US mortality risk over the adult life course. Am J Epidemiol 2013; 177:431-442.

-30 Holme I, Tonstad S: Risk factors and mortality - a follow-up of the Oslo Health Study from 1972-73. Tidsskr Nor Laegeforen 2011;131:456-460.

31 Anderssen SA, Engeland A, Sogaard AJ, Nystad W, Graff-Iversen S, Holme I: Changes in physical activity behavior and the development of body mass index during the last 30 years in Norway. Scand J Med Sci Sports 2008;18:309-317.

32 Vigen R, Ayers C, Willis B, DeFina L, Berry K: Association of cardiorespiratory fitness with total, cardiovascular, and noncardiovascular mortality across 3 decades of follow-up in men and women. Circ Cardiovasc Qual Outcomes 2012;5:358-364.

33 Hart CL, Hole DJ, Davey Smith G: Are two really better than one? Empirical examination of repeat blood pressure measurements and stroke risk in the Renfrew/Paisley and collaborative studies. Stroke 2001;32: 2697-2699.

34 Hart CL, Davey Smith G, Hole DJ, Hawthorne VM: Carboxyhaemoglobin concentration, smoking habit, and mortality in 25 years in the Renfrew/Paisley prospective cohort study. Heart 2006;92:321-324. 